\title{
Determination of Economic Ordering Policies under Trade credit with Application of Zero Acceptance number Single Sampling by Attributes involving Destructive Testing, Inspection Errors
}

\author{
K.Pradeepa Veerakumari ${ }^{1 *}$, H.M. Aruna ${ }^{2}$ \\ ${ }^{1}$ Department of Statistics, Bharathiar University, Coimbatore, Tamil Nadu, India \\ ${ }^{2}$ Department of Statistics, Bharathiar University, Coimbatore, Tamil Nadu, India \\ "Corresponding Author: pradeepaveerakumari@buc.edu.in, Tel.: +91 9443937722
}

Available online at: www.isroset.org

Received: 24/May/2018, Revised: 06/Jun/2018/2018, Accepted: 14/Jun/2018, Online: 30/Jun/2018

\begin{abstract}
Conventional Economic Order Quantity model tacitly assumes that the all items received are perfect. But, however, in practice, the items received may be imperfect. Inspection process helps to identify the defective items. $100 \%$ inspection is not feasible when the testing involved is destructive and costly. Acceptance sampling plan provides fool-proof solution to the problem. It is a trade-off between 100\% inspection and zero inspection. Based on the above conditions, this paper incorporates the Economic Ordering Quantity model with permissible delay in payments and single sampling plan by attributes when the inspection requires destructive testing. Mathematical models are developed to characterize the scenario. Inspection errors are also included in the model. A hypothetical example is illustrated to validate the results in the proposed paper.
\end{abstract}

Keywords - Economic-Order Quantity; Single Sampling plan; Inspection errors; Trade-credit; Destructive testing

\section{INTRODUCTION}

In the manufacturing and assembly industry testing, one of the indispensable tool in assessing the quality of the product. It involves the measurement of quality by comparing to the predetermined standard and specifications. It is crucial when there is a need to make efficient decision with the limited resources. Testing procedures will vary depends on the nature of the product. Some products involve the destructive methods of test. Destructive testing is defined as the test which alters the shape, form or size or structure of the product. The tested product is not available for future use. This test requires a high number of products to test which results in high testing cost also costs consumer a shortage cost and producer gets no return on investment. In order, to keep the costs down, a practical tool for quality assessment is needed.

Acceptance sampling plans consent the predicting the overall quality of a product through the inspection of a relatively small number of samples thus curtailing the redundant costs. It is mainly used when sole purpose of the inspection is to accept or reject the lot. It can be used in quality assessment of the raw materials, finished products etc. Acceptance sampling plans are ideal for the following situations: when the cost of inspection is extravagant; when $100 \%$ inspection is tedious \& exhausting; when inspection requires destructive testing.

When sampling plans involves arrangements for product characteristics that comprises of expensive or destructive testing by attributes a single sampling plan having a zero acceptance number with a small sample size is often engaged in practice. Schilling (1982) specified that in the field of compliance testing, and particularly for safety-related items, zero acceptance number is principally desirable. The small sample size is guaranteed due to the expensive nature of characteristic (OC) curve. According to Dodge (1955), in situations involving small sample size, single sampling plans with smaller acceptance numbers such as $\mathrm{c}=0$ and $\mathrm{c}=1$ can be used. Hahn (1974) has presented that a single sampling plan with zero acceptance number is a minimum sample size plan giving protection to the consumer. Zero acceptance number sampling plans developed by Squeglia (2008), provides better consumer protection. Although, originally developed for military products, these plans are now used in many commercial industries.

Theoretically, the entire acclaimed sampling plan assumes that the inspection process is competently efficient i.e. the defectives are classified correctly as defectives and vice versa. But in practice, the effectiveness of the sampling plan requires the considerations of the presence of inspection 
errors. The primitive reference to inspection errors in statistical quality control literature appears to be Juran(1935) note in Mechanical Engineering. Lavin(1946) modified classical sampling inspection plans by pioneering the concept of effective fraction defective( $\varpi)$ related to true fraction defective $(\omega)$ by the formula

$\varpi=\omega p+(1-\omega) p$

Lavin also stated the scenario's under which inspection errors are committed. Later on many authors for instance, Mc Kenzie(1957), Harris (1968), Minton(1972), Collins(1973), Bennet(1974), Hoag(1975), Kenneth(1975), Dorris(1978), considered inspection errors in the acceptance sampling plan.

Considering inspection error, Salameh(2011) determined the optimal order quantity when the items are of imperfect quality and destructive test emphasizing the zero acceptance number sampling plan. It developed cost function for optimal lot size and sample size constituting shortage cost. Previously all the research papers published on imperfect quality is based on $100 \%$ inspection process. Models with imperfect quality have fascinated many authors leading to immense publications Salamah(2000), Goyal(2002), Papa Christos(2006), Tsou(2007),Hsu(2009),Lin(2010),Jaber(2009 ),Wang(2007), Yoo(2009),Maddah(2009),Rezaei(2005)andW ee(2007), Roy(2011),Erogolou(2007), Wang(2008),Jaber(200 8), Wahab(2010), Khan(2010), Khan(2011).

The main objective of the paper is to study the Salameh's model with permissible delay in payments. Goyal initiated the model for economic ordering quantity with permissible delay in the payments. Enormous research papers are published under the condition of permissible delay in payments. J.T.Teng(2002) amended the Goyal's model by considering varying unit price and unit cost. It is practical and efficient to consider trade credit when evolving the order quantity. So, this study overhauls the Salameh's model under the assumption of permissible delay in payments. Specifically cost function and optimal replenishment cycle time are determined under the conditions of the zero acceptance single sampling plan with inspection error involving destructive testing. Theorems are developed. Simulation is carried out. The paper is organized as follows Section II involves the assumptions of the study, Section III contains the ideology of the model formulation and the total costs involved in the study. Section IV consists of cost optimization theory and techniques. Section 5 includes the theorems .Numerical illustrations are provided in the section 6 and the conclusion are given in the section 6 .

\section{ASSUMPTIONS}

- The following assumptions are used in the study. The single sampling procedure is applied under the conditions of binomial distribution with parameters $\mathrm{c}, \mathrm{n}, \mathrm{p}_{\mathrm{e}}$.
- $\quad$ The acceptance number is considered as zero.

- Inspection process is imperfect with errors.

- Sampling is done without replacement.

- The replenishment order is dispatched rapidly.

- $\quad$ Lead time is zero.

- Demand is known and constant.

- $\quad$ Single product inventory is considered.

- The vendor grant to settle the account for the items replenished in credit period $\mathbf{M}$, during which interest is earned on the sales earnings at the rate of $\mathrm{I}_{\mathrm{e}}$ per unit. Thenceforth, the interest is to paid at the rate of $I_{p}$ per unit on the stockpiled items.

- $\quad \mathrm{W}<\mathrm{P}, \mathrm{I}_{\mathrm{e}}<\mathrm{I}_{\mathrm{p}}$

\section{MOdel Formulation And Total Costs INVOLVED}

In the study, it is assumed that the buyer uses the acceptance sampling procedure to locate the defects. The sampling is done without replacement based on destructive testing. Total costs included in the model are ordering costs, holding cost, inspection cost, acceptance cost. The model is formulated in such a way that the items of the rejected lot are sold.

Consider that the consumer places a order of $\mathrm{Q}$ to the producer. The ordering cost is fixed and denoted as $c_{o}$ and Demand rate D. After receiving the lot, testing is done on the sample of size n. Proportion defective in the lot is p. It is assumed that single sampling by attributes is carried out with some inspection error.$e_{1}$ is the probability of committing type I error where defective is classified as nondefective. $\mathrm{e}_{2}$ is the probability of committing type II error i.e. classifying non-defective as defective. The executing procedure of the single sampling plan as in Schilling (1982) is as follows:

1. A Random sample of size $\mathrm{n}$ is taken from a lot of size $\mathrm{N}$

2. The number of defectives $d$ is counted and compared to the acceptance number $\mathrm{c}$. If $\mathrm{d}<\mathrm{c}$, the lot is accepted or otherwise rejected.

The probability of the acceptance of the lot is

$\mathrm{p}_{\mathrm{a}}=\sum_{\mathrm{d}=0}^{\mathrm{c}}\left(\begin{array}{l}\mathrm{n} \\ \mathrm{d}\end{array}\right) \mathrm{p}^{\mathrm{d}}(1-\mathrm{p})^{\mathrm{n}-\mathrm{d}}$

Satisfying the conditions,

$$
\text { - } \quad \mathrm{P}_{\mathrm{a}}\left(\mathrm{p}_{1}\right) \leq 1-\alpha \&
$$


- $\quad \mathrm{P}_{\mathrm{a}}\left(\mathrm{p}_{2}\right) \geq \beta$

Since in case of destructive testing, it is in practice to use acceptance number .Then the probability of acceptance becomes,

$\mathrm{P}_{\mathrm{a}}=(1-\mathrm{p})^{\mathrm{n}}$

Since the inspection process involves the errors, the apparent fraction defective $p_{e}$ can be expressed as a function of the known true fraction defective $\mathrm{p}$,

$\mathrm{p}_{\mathrm{e}}=\mathrm{p}\left(1-\mathrm{e}_{2}\right)+(1-\mathrm{p}) \mathrm{e}_{1}$

By substituting in eqn (1), obtaining,

$\mathrm{p}_{\mathrm{a}_{\mathrm{e}}}=\left[\left(1-\mathrm{e}_{1}\right)(1-\mathrm{p})+\mathrm{p}\left(\mathrm{e}_{2}\right)\right]^{\mathrm{n}}$

Since, the process involves zero acceptance sampling plan the sample size $\mathrm{n}$ can be obtained by using $\beta$ and LQL . where $\beta$ representing consumer risk, LQL representing the probability of accepting rejectable quality. It is assumed that the inspection is faulty with inspection error then the LQL is replaced by $\mathrm{LQL}^{\prime}=\mathrm{e}_{1}(1-\mathrm{LQL})+\left(1-\mathrm{e}_{2}\right) \mathrm{LQL}$

$\mathrm{n}=\frac{\log \beta}{\log \left(1-\mathrm{LQL}^{\prime}\right)}$

When a lot is accepted the number of shortage items in the lot is (DT-n) $p_{e}+n$. Then the cost of accepting the lot is $\left.\mathrm{c}_{\mathrm{a}(\mathrm{DT}}(\mathrm{n})+\mathrm{n}\right) \mathrm{p}_{\mathrm{a}}$.If the lot is rejected then, it is sold at reduced rate $\mathrm{k}$ per unit. Then the cost associated with the rejection is $\mathrm{K}(\mathrm{DT}-\mathrm{n}) / \mathrm{T}$. Then the other costs associated with the model is

i. Annual Ordering cost $=\frac{C_{O}}{T}$

ii. Annual Inventory Holding Cost $=\frac{(\mathrm{DT}-\mathrm{n})^{2} \mathrm{C}_{\mathrm{h}}}{2 \mathrm{DT}}(10)$

iii. Annual Cost of Inspection

The expected number of units destructed in a sample of size $\mathrm{n}$, providing the fraction defective $\mathrm{p}_{\mathrm{e}}$ is $n \mathrm{p}_{\mathrm{e}}$. Then the expected cost of inspection is $n\left(c_{i}+c_{d} \cdot p\right)$

Annual Cost of Inspection $=\frac{n\left(c_{i}+c_{d} \cdot p_{e}\right)}{T}$

iv. Annual Interest Earned is twofold

1. When $\mathrm{T} \geq \mathrm{M}$

Annual Interest Earned $=\frac{\text { P.I } \cdot \mathrm{I}_{\mathrm{e}} \cdot \mathrm{DM}^{2}}{2 \mathrm{~T}}$

2. When $\mathrm{T} \leq \mathrm{M}$

Annual Interest Earned $=\frac{\text { P.I } \mathrm{I}_{\mathrm{e}} \cdot \mathrm{DT}}{2}+\mathrm{P} \cdot \mathrm{I}_{\mathrm{e}} \cdot \mathrm{D}(\mathrm{M}-\mathrm{T})$

v.Annual Interest Paid

1. When $\mathrm{T} \geq \mathrm{M}$

Annual Interest paid $=\frac{\text { WD.I } \cdot(T-M)^{2}}{T}$

2. When $\mathrm{T} \leq \mathrm{M}$
Annual Interest charge $=0$. In this case, no interest charge is paid for the items.

It is assumed that when the lot is rejected the consumer sells the defective items at reduced cost, and then places a new order.

1. When $\mathrm{T} \geq \mathrm{M}$,

when the lot is accepted at the first time, the total cost becomes,

$\operatorname{Tc}_{1}(T)=\left(\begin{array}{l}\frac{c_{o}}{T}+\frac{(D T-n)^{2} c_{h}}{2 D T}+\frac{\left(c_{i}+c_{d} \cdot p_{e}\right) \cdot n}{T}+\frac{c_{a}\left((D T-n) p_{e}+n\right)}{T} \\ -\frac{\text { P.I } I_{e} \cdot D M^{2}}{2 T}+\frac{\text { W.D.I } I_{p}(T-M)^{2}}{2 T}, p_{a}\end{array}\right)$

If the lot is rejected for the first time sold the items (DT-n) in reduced rate, then the consumer reorder the lot. If that reordered lot is accepted, cost function then becomes,

$T c_{1}(T)=$

$\left(\begin{array}{l}2\left(\frac{c_{0}}{T}+\frac{\left(c_{i} \cdot+c_{d} \cdot P_{e}\right) n}{T}\right)-\frac{K(D T-n)}{T}+\frac{(D T-n)^{2} c_{h}}{2 D T}+\frac{c_{a}\left((D T-n) p_{e}+n\right)}{T} \\ -\frac{P^{2} I_{e} \cdot D M^{2}}{2 T}+\frac{W \cdot D \cdot I_{p}(T-M)^{2}}{2 T},\left(1-p_{a}\right) p_{a}\end{array}\right)(16)$

Expanding up to $\mathrm{i}^{\text {th }}$, the expected total cost becomes, $\mathrm{E}\left(\mathrm{Tc}_{1}(\mathrm{~T})\right)=$

$\left(\begin{array}{l}\mathrm{p}_{\mathrm{a}} \sum_{\mathrm{i}=0}^{\infty}\left[(1+\mathrm{i})\left(\frac{\mathrm{c}_{\mathrm{o}}}{\mathrm{T}}+\frac{\left(\mathrm{c}_{\mathrm{i}}+\mathrm{c}_{\mathrm{d}} \cdot \mathrm{p}_{\mathrm{e}}\right) \mathrm{n}}{\mathrm{T}}\right)-\mathrm{i} \frac{\mathrm{K}(\mathrm{DT}-\mathrm{n})}{\mathrm{T}}+\frac{(\mathrm{DT}-\mathrm{n})^{2} \mathrm{c}_{\mathrm{h}}}{2}\right. \\ \left.+\frac{\mathrm{c}_{\mathrm{a}}\left((\mathrm{DT}-\mathrm{n}) \mathrm{p}^{*}+\mathrm{n}\right)}{\mathrm{T}}-\frac{\text { P.I } \mathrm{I}_{\mathrm{e}} \cdot \mathrm{DM} \mathrm{M}^{2}}{2 \mathrm{~T}}+\frac{\text { W.D.I. } \mathrm{I}_{\mathrm{p}}(\mathrm{T}-\mathrm{M})^{2}}{2 \mathrm{~T}}\right],\left(1-\mathrm{p}_{\mathrm{a}}\right)^{\mathrm{i}}\end{array}\right)(17)$

The results of this series expansion are converging,

$\sum_{\mathrm{i}=0}^{\infty}\left[(1+\mathrm{i})\left(1-\mathrm{p}_{\mathrm{ae}}\right)^{\mathrm{i}}\right]=\frac{1}{\mathrm{p}_{\mathrm{ae}}^{2}}$

$\sum_{\mathrm{i}=0}^{\infty} \mathrm{i}\left(1-\mathrm{p}_{\mathrm{ae}}\right)^{\mathrm{i}}=\frac{1-\mathrm{p}_{\mathrm{a}}}{\mathrm{p}_{\mathrm{ae}}^{2}}$

$\sum_{\mathrm{i}=\mathrm{o}}^{\infty}\left(1-\mathrm{p}_{\mathrm{a}}\right)^{\mathrm{i}}=\frac{1}{\mathrm{p}_{\mathrm{ae}}}$

Substituting the values of the eqn 18to 20 in 17 , the total expected cost function becomes,

$\mathrm{E}\left(\mathrm{Tc}_{1}(\mathrm{~T})\right)=$
$\left(\begin{array}{l}\left(\frac{c_{\mathrm{o}}}{\mathrm{T}}+\frac{\left(c_{\mathrm{i}}+\mathrm{c}_{\mathrm{d}} \cdot \mathrm{p}_{\mathrm{e}}\right) \cdot \mathrm{n}}{\mathrm{T}}\right) \frac{1}{\mathrm{p}_{\mathrm{ae}}}-\frac{\mathrm{K}(\mathrm{DT}-\mathrm{n})}{\mathrm{T}} \frac{1-\mathrm{p}_{\mathrm{ae}}}{\mathrm{p}_{\mathrm{ae}}}+\frac{(\mathrm{DT}-\mathrm{n})^{2} \mathrm{c}_{\mathrm{h}}}{2 \mathrm{DT}} \\ -\frac{\mathrm{P} \cdot \mathrm{I}_{\mathrm{e}} \cdot \mathrm{DM}^{2}}{2 \mathrm{~T}}+\frac{\mathrm{c}_{\mathrm{a}}\left((\mathrm{DT}-\mathrm{n}) \mathrm{p}_{\mathrm{e}}+\mathrm{n}\right)}{\mathrm{T}}+\frac{\text { W.D.I } \mathrm{I}_{\mathrm{p}}(\mathrm{T}-\mathrm{M})^{2}}{2 \mathrm{~T}}\end{array}\right)(2 \mathrm{l})$

Since the zero acceptance number sampling plan is implied, then $p_{a \mathrm{e}}=(1-\mathrm{p})^{\mathrm{n}}$, thus reducing the cost function to,

$\mathrm{Tc}_{1}(\mathrm{~T})=$ 


$$
\left(\begin{array}{l}
\left(\frac{c_{\mathrm{o}}}{\mathrm{T}}+\frac{\left(\mathrm{c}_{\mathrm{i}}+\mathrm{c}_{\mathrm{d}} \cdot \mathrm{p}_{\mathrm{e}}\right) \cdot \mathrm{n}}{\mathrm{T}}\right) \frac{1}{\left(1-\mathrm{p}_{\mathrm{e}}\right)^{\mathrm{n}}}-\frac{\mathrm{K}(\mathrm{DT}-\mathrm{n})}{\mathrm{T}} \frac{1-\left(1-\mathrm{p}_{\mathrm{e}}\right)^{\mathrm{n}}}{\left(1-\mathrm{p}_{\mathrm{e}}\right)^{\mathrm{n}}} \\
+\frac{(\mathrm{DT}-\mathrm{n})^{2} \mathrm{c}_{\mathrm{h}}}{2 \mathrm{DT}}+\frac{\mathrm{c}_{\mathrm{a}}\left((\mathrm{DT}-\mathrm{n}) \mathrm{p}_{\mathrm{e}}+\mathrm{n}\right)}{\mathrm{T}} \\
-\frac{\text { P.I } \mathrm{I}_{\mathrm{e}} \cdot \mathrm{DM} \mathrm{M}^{2}}{2 \mathrm{~T}}+\frac{\text { W.D.I } \mathrm{p}(\mathrm{T}-\mathrm{M})^{2}}{2 \mathrm{~T}}
\end{array}\right.
$$

Similarly, total cost of $\mathrm{TC}_{2}(\mathrm{~T})$ when $\mathrm{T} \leq \mathrm{M}$, is obtained as,

$$
\begin{aligned}
& \operatorname{Tc}_{2}(T)= \\
& \left(\begin{array}{l}
\left(\frac{c_{O}}{T}+\frac{\left(c_{i}+c_{d} \cdot p_{e}\right) \cdot n}{T}\right) \frac{1}{\left(1-p_{e}\right)^{n}}-\frac{K(D T-n)}{T} \frac{1-\left(1-p_{e}\right)^{n}}{\left(1-p_{e}\right)^{n}} \\
+\frac{(D T-n)^{2} c_{h}}{2 D T}+\frac{c_{a}\left((D T-n) p_{e}+n\right)}{T}-\frac{P \cdot I_{e} \cdot D T}{2}-P . I_{e} D(M-T)
\end{array}\right)
\end{aligned}
$$

Total cost is defined only on the condition that, $\mathrm{T}>0$. Relevant details should be given including experimental design and the technique (s) used along with appropriate statistical methods used clearly along with the year of experimentation (field and laboratory).

\section{COST OPTIMIZATION THEORY AND TECHNIQUES}

Cost optimization is necessary conditions for the profit maximization of management. In cost optimization techniques, the convexity of the twice differentiable is important \& well-known implications. It comprehends the subsequent steps

- A cost function is convex if and only if the first order derivative $f^{1}(x)$ is decreasing fun

- $\quad \mathrm{f}^{11}(\mathrm{x}) \geq 0$

- In order to optimize the cost function and to determine the optimal replenishment cycle time, first order and second order derivative function of $\mathrm{TC}_{1}(\mathrm{~T}), \mathrm{TC}_{2}(\mathrm{~T})$ with respect to $\mathrm{T}$ are obtained.

$\operatorname{Tc}_{1}^{\prime}(T)=\frac{1}{2 D T^{2}\left(1-p_{e}\right)^{n}}\left(\begin{array}{l}-2 D\left(c_{o}+\left(c_{i}+c_{d} \cdot p_{e}\right) \cdot n\right)-2 k n\left(1-\left(1-p_{e}\right)^{n}\right) \\ -n^{2}\left(c_{h}\right)\left(1-p_{e}\right)^{n}+2 D c_{a}\left(\left(p_{e}-1\right)+n\right)\left(1-p_{e}\right)^{n} \\ -D^{2} M^{2}\left(W \cdot I_{p}-P \cdot I_{e}\right)\left(1-p_{e}\right)^{n}+ \\ D^{2} T^{2}\left(c_{h}+W \cdot I_{p}\right)\left(1-p_{e}\right)^{n}\end{array}\right)$

$\operatorname{Tc}_{1}^{\prime \prime}(T)=\frac{1}{D^{3}\left(1-p_{e}\right)^{n}}\left(\begin{array}{l}2 D\left(c_{o}+\left(c_{i}+c_{d} \cdot p_{e}\right) \cdot n\right)+2 k n\left(1-\left(1-p_{e}\right)^{n}\right)-n^{2} c_{h}\left(1-p_{e}\right)^{n} \\ +2 D\left(c_{a}(-n) p_{e}+n\right)\left(1-p_{e}\right)^{n}+D^{2} M^{2}\left(W \cdot I_{p}-P \cdot I_{e}\right)\left(1-p_{e}\right)^{n}\end{array}\right)(25)$

$\mathrm{TC}_{2}^{\prime}(\mathrm{T})=\frac{1}{2 \mathrm{DT}^{2}\left(1-\mathrm{p}_{\mathrm{e}}\right)^{\mathrm{n}}}\left(\begin{array}{l}-2 \mathrm{D}\left(\mathrm{c}_{\mathrm{o}}+\left(\mathrm{c}_{\mathrm{i}}+\mathrm{c}_{\mathrm{d}} \cdot \mathrm{p}_{\mathrm{e}}\right) \cdot \mathrm{n}\right)-2 \mathrm{kn}\left(1-\left(1-\mathrm{p}_{\mathrm{e}}\right)^{\mathrm{n}}\right) \\ -2 \mathrm{D}\left(\mathrm{c}_{\mathrm{a}}\left(\left(\left(\mathrm{p}_{\mathrm{e}}-1\right)+\mathrm{n}\right)\left(1-\mathrm{p}_{\mathrm{e}}\right)^{\mathrm{n}}-\mathrm{n}^{2} \cdot \mathrm{c}_{\mathrm{h}}\left(1-\mathrm{p}_{\mathrm{e}}\right)^{\mathrm{n}}\right.\right. \\ +\mathrm{D}^{2} \mathrm{~T}^{2}\left(\mathrm{c}_{\mathrm{h}}+\mathrm{P} \cdot \mathrm{I}_{\mathrm{e}}\right)\left(1-\mathrm{p}_{\mathrm{e}}\right)^{\mathrm{n}}\end{array}\right)(26)$
$\mathrm{TC}_{2}^{\prime \prime}(\mathrm{T})=\frac{1}{\mathrm{DT}^{3}\left(1-\mathrm{p}_{\mathrm{e}}\right)^{\mathrm{n}}}\left(\begin{array}{l}2 \mathrm{D}\left(\mathrm{c}_{\mathrm{o}}+\left(\mathrm{c}_{\mathrm{i}}+\mathrm{c}_{\mathrm{d}} \cdot \mathrm{p}_{\mathrm{e}}\right) \cdot \mathrm{n}\right)+2 \mathrm{kn}\left(1-\left(1-\mathrm{p}_{\mathrm{e}}\right)^{\mathrm{n}}\right) \\ +2 \mathrm{D}\left(\mathrm{c}_{\mathrm{a}}\left((-\mathrm{n}) \mathrm{p}_{\mathrm{e}}+\mathrm{n}\right)\left(1-\mathrm{p}_{\mathrm{e}}\right)^{\mathrm{n}}-\mathrm{n}^{2} \mathrm{c}_{\mathrm{h}}\left(1-\mathrm{p}_{\mathrm{e}}\right)^{\mathrm{n}}\right.\end{array}\right)(27)$

The optimal replenishment cycle time associated with least possible cost is obtained when; the non-negative term of first order derivative is equated to zero. Then by equating equations $24 \& 26$ to zero, the values of $\mathrm{T}_{1}{ }^{*}$ and $\mathrm{T}_{2}{ }^{*}$ are obtained.

$$
\begin{aligned}
& \mathrm{T}_{1}^{*}=\left(\begin{array}{l}
\frac{1}{\mathrm{D}^{2}\left(\mathrm{c}_{\mathrm{h}}+\mathrm{W} \cdot \mathrm{I}_{\mathrm{p}}\right)\left(1-\mathrm{p}_{\mathrm{e}}\right)^{\mathrm{n}}}\left(2 \mathrm { D } \left(\left(\mathrm{c}_{\mathrm{o}}+\left(\mathrm{c}_{\mathrm{i}}+\mathrm{c}_{\mathrm{d}} \cdot \mathrm{p}_{\mathrm{e}}\right) \cdot \mathrm{n}\right)+2 \mathrm{kn}\left(1-\left(1-\mathrm{p}_{\mathrm{e}}\right)^{\mathrm{n}}\right)\right.\right. \\
+\left(\mathrm{c}_{\mathrm{a}}\left(\left(\left(\mathrm{p}_{\mathrm{e}}-1\right)+\mathrm{n}\right)\left(1-\mathrm{p}_{\mathrm{e}}\right)^{\mathrm{n}}\right)-\mathrm{n}^{2} \mathrm{c}_{\mathrm{h}}\left(1-\mathrm{p}_{\mathrm{e}}\right)^{\mathrm{n}}\right. \\
\left.-\mathrm{D}^{2} \mathrm{M}^{2}\left(\mathrm{~W} \cdot \mathrm{I}_{\mathrm{p}}-\mathrm{P} \cdot \mathrm{I}_{\mathrm{e}}\right)\left(1-\mathrm{p}_{\mathrm{e}}\right)^{\mathrm{n}}\right)
\end{array}\right)^{1 / 2} \\
& \mathrm{~T}_{2}^{*}=\left(\begin{array}{l}
\frac{1}{\mathrm{D}^{2}\left(\mathrm{c}_{\mathrm{h}}+\mathrm{P} \cdot \mathrm{I}_{\mathrm{e}}\right)\left(1-\mathrm{p}_{\mathrm{e}}\right)^{\mathrm{n}}}\left(2 \mathrm { D } \left(\left(\mathrm{c}_{\mathrm{o}}+\left(\mathrm{c}_{\mathrm{i}}+\mathrm{c}_{\mathrm{d}} \cdot \mathrm{p}_{\mathrm{e}}\right) \cdot \mathrm{n}\right)+\mathrm{kn}\left(1-\left(1-\mathrm{p}_{\mathrm{e}}\right)^{\mathrm{n}}\right)\right.\right. \\
+\left(\mathrm{c}_{\mathrm{a}}\left(\left(\mathrm{p}_{\mathrm{e}}-1\right)+\mathrm{n}\right)\left(1-\mathrm{p}_{\mathrm{e}}\right)^{\mathrm{n}}\right)
\end{array}\right)^{1 / 2}
\end{aligned}
$$

The total cost function,

$$
T c(T)=\left\{\begin{array}{l}
T c_{1}(T), T \geq M \\
T c_{2}(T), T \leq M
\end{array}\right.
$$

Consider, $\mathrm{C}=$

$$
2 \mathrm{D}\left(\left(\mathrm{c}_{\mathrm{o}}+\left(\mathrm{c}_{\mathrm{i}}+\mathrm{c}_{\mathrm{d}} \cdot \mathrm{p}_{\mathrm{e}}\right) \cdot \mathrm{n}\right)+2 \mathrm{kn}\left(1-\left(1-\mathrm{p}_{\mathrm{e}}\right)^{\mathrm{n}}\right)\right.
$$$$
+\left(c_{a}\left((-n) p_{e}+n\right)\left(1-p_{e}\right)^{n}\right)-n^{2} c_{h}\left(1-p_{e}\right)^{n}
$$

$\Delta=\frac{\mathrm{DM}^{2}\left(\mathrm{c}_{\mathrm{h}}+\mathrm{P} . \mathrm{I}_{\mathrm{e}}\right)}{2}-\mathrm{C}$.Let $\mathrm{T}^{*}$ denote the point where total cost is least possible. Inreality, both, $\frac{\mathrm{DM}^{2} \mathrm{c}_{\mathrm{h}}}{2} \& \frac{\mathrm{DM}^{2} \mathrm{P} . \mathrm{I}_{\mathrm{e}}}{2}$ represents stock holding cost excluding interest charges for the trade credit.

\section{THEOREM}

(i)If $\Delta>0$, Then the optimal replenishment cycle associated with the least possible cost is $\mathrm{T}^{*}=\mathrm{T}_{2}{ }^{*}, \mathrm{~T} \leq \mathrm{M}$.

(ii)If $\Delta<0$, Then the optimal replenishment cycle associated with the least possible cost is $\mathrm{T}^{*}=\mathrm{T}_{1}{ }^{*}, \mathrm{~T} \geq \mathrm{M}$.

(ii)If $\Delta=0$, Then the optimal replenishment cycle associated with the least possible cost is $\mathrm{T}^{*}=\mathrm{T}_{1}{ }^{*}=\mathrm{T}_{2}, \mathrm{~T}=\mathrm{M}$.

Proof:

(i)If $\Delta>0$, then $\mathrm{TC}_{1}(\mathrm{~T})>0, \mathrm{TC}_{2}(\mathrm{~T})>0$. Hence total cost has minimum value at $\mathrm{Tc}_{1}(\mathrm{~T})$ is minimum at $\mathrm{M}$, leads to $\mathrm{Tc}_{2}\left(\mathrm{~T}_{2}{ }^{*}\right) \leq . \mathrm{Tc}_{2}(\mathrm{M})=\mathrm{Tc}_{1}(\mathrm{M})$ therefore the minimum value at $\mathrm{T}_{2}{ }^{*}$ leads to $\mathrm{Tc}_{2}{ }^{*}$ with least possible minimum cost.

(ii)If $\Delta<0$, then $\mathrm{TC}_{1}(\mathrm{~T})<0, \mathrm{TC}_{2}(\mathrm{~T})<0$. Hence total cost has minimum value at $\mathrm{Tc}_{2}(\mathrm{~T})$ is minimum at $\mathrm{M}$, leads to $\mathrm{Tc}_{2}\left(\mathrm{M}^{*}\right)=\mathrm{Tc}_{2}(\mathrm{M}) \leq \mathrm{Tc}_{1}\left(\mathrm{~T}_{1}\right)$ therefore the minimum value at $\mathrm{T}_{2}{ }^{*}$ leads to $\mathrm{Tc}_{1}{ }^{*}$ with least possible minimum cost.

(iii)If $\Delta=0$, then $\mathrm{TC}_{1}(\mathrm{~T})=0, \mathrm{TC}_{2}(\mathrm{~T})=0$.Hence total cost has minimum value at $\mathrm{Tc}_{1}(\mathrm{M})=\mathrm{Tc}_{2}(\mathrm{M})$ is minimum at $\mathrm{M}$, leads 
to $\mathrm{Tc}_{2}(\mathrm{M})=\mathrm{Tc}_{1}(\mathrm{M})$ therefore the minimum value at $\mathrm{M}=\mathrm{T}^{*}{ }_{1=}$ $\mathrm{T}_{2}{ }^{*}$ leads to $\mathrm{Tc}^{*}=\mathrm{Tc}\left(\mathrm{T}_{1}{ }^{*}=\mathrm{Tc}\left(\mathrm{T}_{2}{ }^{*}\right)\right.$ with least possible minimum cost.

The main conclusions of the study may be presented in a short Conclusion Section. In this section, the author(s) should also briefly discuss the limitations of the research and Future Scope for improvement.

\section{NUMERICAL ILLUSTRATIONS}

To illustrate the results, proposed method is applied to hypothetical numerical examples where the associated costs and parameters are, $\mathrm{c}_{0}=\$ 50, \mathrm{c}_{\mathrm{i}}=\$ 0.1$ perunit; $\mathrm{c}_{\mathrm{d}}=\$ 0.2$ perunit; $\mathrm{c}_{\mathrm{h}}=0.5 ; \mathrm{D}=1000 ; \mathrm{k}=0.05 ; \mathrm{M}=0.5 ; \mathrm{c}_{\mathrm{a}}=0.7 ; \mathrm{W}=5$ per unit $; \mathrm{P}=7 ; \mathrm{I}_{\mathrm{e}}=.10 ; \mathrm{I}_{\mathrm{p}}=.15 ; \beta=0.1 ; \mathrm{p}=0.1 ;$ in appropriate units. Based on the theorem, for various integral values of $L Q L, e_{1}, e_{2}$, the corresponding values of $\mathrm{n}, \mathrm{T}^{*}, \mathrm{Tc}$ are obtained. Computed results are presented in the table 1 . Results from the table shows that the Tc is reduced with the reduction inspection errors. With the increase in inspection errors the total cost also increases.

Table 1: total cost and associated optimal replenishment time for different values of errors in dollars.

\begin{tabular}{|cccccc|}
\hline LQL & $\mathrm{e}_{1}$ & $\mathrm{e}_{2}$ & $\mathrm{n}$ & $\mathrm{T}^{*}$ & $\mathrm{TC}\left(\mathrm{T}^{*}\right)$ \\
\hline 0.05 & 0.05 & 0.06 & 21 & $\mathrm{~T}_{1}{ }^{*}=0.5388$ & 250.91 \\
\hline 0.05 & 0.06 & 0.07 & 19 & $\mathrm{~T}_{1}{ }^{*}=0.5590$ & 268.00 \\
\hline 0.05 & 0.07 & 0.08 & 18 & $\mathrm{~T}_{1}{ }^{*}=0.5940$ & 290.85 \\
\hline 0.05 & 0.08 & 0.09 & 16 & $\mathrm{~T}_{1}{ }^{*}=0.5952$ & 297.57 \\
\hline
\end{tabular}

\section{CONCLUSION}

This study integrates the trade credit and acceptance sampling by attributes with zero acceptance number in the integrated producer-consumer model and developed theorems. Theorem demonstrates that by computing $\Delta$, the optimal replenishment cycle $\mathrm{T}_{1}{ }^{*}$ and $\mathrm{T}_{2}{ }^{*}$ with least possible costs are determined. The theorem efficiently simplifies the solution procedure. By including the inspection error in the model, the consequence is mitigated by expending the resources. Future research focuses on the applying the EOQ model with permissible delay in payments with nondestructive system and applying to other acceptance sampling plans such as SkSP-2, QSS-1.

\section{REFERENCES}

[1].G.Bennet,E.Kenneth \& J.W.Schimdt, "The economic effects of inspector error on attribute sampling plans",Naval Research Logistics,vol21,No3, pp431-443,1974.

[2].R.D.Collins,K.E.Case.K.E\&G.K.Bennett.,"The Effects of Inspection error on Single sampling Inspection Plans", International journal of Production Research,Vol11,No3,pp 289-298,1973.

[3].H.F. Dodge," Chain sampling inspection plans”, Industrial Quality Control,Vol 11,pp10-13,1955
[4].A.L.Dorris\& B.L.Footie.,Inspection errors \& Statistical Quality Control -A Survey"AIEE Transactions, Vol 10, No2,pp184192,1978 .

[5]A..Eroglu and G.Ozdemir, "An Economic Order Quantity Model with Defective Items and Shortages", International Journal of Production Economics, Vol106, No 2, pp544-549, 2007.

[6]K..Govindaraju,'Inspection Error Adjustment in the design of single sampling attribute plan",Quality Engineering,vol19,No3,pp227233,2007

[7].S.K.Goyal,"Economic order quantity under conditions of permissible delay in payments", Journal of operational research society, vol36,No4, pp335-338,1985.

[8].S.K.Goyal and L.E.Cardenas-Barron, "Note On: Economic Production Quantity Model for Items with Imperfect Quality - A Practical Approach, International Journal of Production Economics, vol77, No1, pp85-87,2002.

[9]G.J.Hahn,"Minimum size sampling plans", Journal of Quality Technology,vol 6, pp 121-127,1974

[10].D.H.Harris.,"Effect of Defect Rate on Inspection Accuracy",Journal of Applied psychology,vol52,No5,pp236237,1968 .

[11]. L.L.Hoag.L.Laverene, L.F.Bobbie ,Clark Mount-campbell,’The Effect of Inspector Accuracy on the Type I and Type II Errors of Common Sampling Techniques"Journal of Quality Technology,vol7,No4, pp157-164,1975

[12]. W.K.Hsu andH. Yu.," EOQ Model for Imperfective Items Under A One-Time-Only Discount", Omega, vol37,No5, pp1018$1026,2009$.

[13].M.Y. Jaber,S.K Goyal andM. Imran, "Economic Production Quantity Model for Items with Imperfect Quality Subject to Learning Effects", International Journal of Production Economics, vol115,No1, pp143-150,2008.

[14]. M.Y.Jaber, M.Bonney and I.Moualek, "An Economic Order Quantity Model for An Imperfect Production Process with Entropy Cost", International Journal of Production Economics, vol118,No1, pp26-33,2009.

[15]J.M..Juran.,'Inspectors Errors in Quality Control",Mechanical Engineering,vol 57,pp643-644,1935.

[16].E.C.Kenneth,K.G.Bennet.G,J.W.Schmidt,"The Effect of Inspection Error on Average Outgoing Quality",Journal of Quality Technology,vol7,No1,pp 28-32,1975.

[17].M. Khan.M, M.Y.Jaber and M.I.M.Wahab, "Economic Order Quantity Model for Items with Imperfect Quality with Learning in Inspection", International Journal Of Production Economics, Vol124,No1, pp87-96,2010.

[18].M.Khan.M, M.Y. Jaber andM. Bonney, "An Economic Order Quantity (EOQ) for Items with Imperfect Quality and Inspection Errors", International Journal of Production Economics, vol133, pp113-118,2011.

[19]M..Lavin," Inspection Efficiency and Sampling Inspection Plans", Journal of the American Statistical Association,vol41,No236,432$438,1946$.

[20].T. Lin., "An Economic Order Quantity With Imperfect Quality And Quantity Discounts", Applied Mathematical Modelling, vol34,No10, 3158-3165,2010.

[21].B.Maddah.B., M.K.Salameh and G.M. Karame, "Lot Sizing with Random Yield and Different Qualities", Applied Mathematical ModellingVol, 33,No4, 2009.

[22]. B.Maddah and M.Y.Jaber,"Economic Order Quantity for Items with Imperfect Quality: Revisited", International Journal of Production Economics, vol112,No2, pp808-815,2008.

[23]R.M..McKenzie,"On the Accuracy of Inspectors",Erogonomics,vol1,pp258-270,1957. 
[24]G..Minton,"Verification Error in Single Sampling Inspection Plans",Journal of the American Statistical Association,vol67,No337, 46-54,1972.

[25].S.Papachristos and I. Konstantaras, "Economic Ordering Quantity Models for Items with Imperfect Quality", International Journal of Production Economics, vol 100, No1,pp148-154,2006.

[26]. J.Rezaei, "Economic Order Quantity Model with Backorder for Imperfect Quality Items", Proceedings of the IEEE International Engineering Management Conference, vol2, pp466-470, 2005.

[27]M.D..Roy,S.S. Sana\& K.Chaudri," An economic order quantity model of imperfect quality items with partial backlogging",International Journal of System Sciences, vol42,No8, pp 255-265,2011.

[28]. M.K.Salameh and M.Y.Jaber, "Economic Production Quantity Model for Items with Imperfect Quality", International Journal of Production Economics, vol64,No1-3, pp59-64,2000.

[29].M.Salamah,"Economic Order Quantity with Imperfect Quality, Destructive testing acceptance sampling, and inspection errors",Advances in Management \& Applied Economics,vol1,No2,pp 59-75,2011.

[30].E.G. Schilling, Acceptance Sampling in Quality Control (New York: Marcel Dekker), 1982.

[31]. N.L.Squeglia,"Zero acceptance number sampling plans",fifth edition, American Society for Quality, Quality Press,2008.

[32].J.T.Teng.." on the economic order quantity under conditions of permissible delay in payments", Journal of operational research society, Vol53,No8pp,915-918,2002.

[33]. J.Tsou.," Economic Order Quantity Model and Taguchi's Cost Of Poor Quality", Applied Mathematical Modelling, vol31,No2, pp283-291,2007.

[34].M.I.M.Wahab andM.Y.Jaber,"Economic Order Quantity Model for Items with Imperfect Quality, Different Holding Costs, and Learning Effects: ANote", Computers \& Industrial Engineering, vol58,No1, pp186-190,2010.
[35]. X.Wang, W.Tang and R.Zhao, "Random Fuzzy EOQ Model with Imperfect Quality Items", Fuzzy Optimization and Decision Making, vol6,No2, pp139-153,2007.

[36].X.Wang, W. Tang, Y. Sai and K.Zhang, "Fuzzy Random EOQ Model with Defective Items and Shortages", IEEE International Conference on Networking, Sensing and Control, pp107110,2008 .

[37].H.M.Wee., J.Yu and M.C.Chen, "Optimal Inventory Model for Items with Imperfect Quality and Shortage Backordering", Omega, vol35,No1, pp7-11,2007.

[38].S.H.Yoo,D.S.Kim,H.S.Park,"Economic Production Quantity Model with Imperfect-Quality Items,Two-way Imperfect Inspection and Sales Return",International Journal of Production Economics,vol 121,No1,pp 255-265,2009.

\section{Authors Profile}

K. Pradeepa Veerakumari pursued M.Sc., and Ph.D., Statistics from Bharathiar University, Coimbatore in 2004 \& 2009. She is currently working as Assistant Professor in Department of Statistics from Bharathiar university, Coimbatore since 2011. She is a member of ISPS, IISA since 2011 and Life member of ISPS since 2011. She has published more than 20 research papers in reputed international journals including Thomson Reuters (SCI/SCI-E \& Web of Science, Scopus, Google Scholar) and it's also available online. Her main research work focuses on Statistical Quality Control, Neural Network, Bayesian sampling and Expert system. She has 9 years of teaching experience and 14 years of research experience. H.M. Aruna is currently pursuing her Ph. D in the department of statistics, Bharathiar University, Coimbatore. 